\title{
Development of GABAergic Inputs Is Not Altered in Early Maturation of Adult Born Dentate Granule Neurons in Fragile X Mice
}

\author{
Christine L. Remmers ${ }^{1}$ and ${ }^{(0)}$ Anis Contractor ${ }^{1,2}$ \\ https://doi.org/10.1523/ENEURO.0137-18.2018 \\ ${ }^{1}$ Department of Physiology, Feinberg School of Medicine, Northwestern University, Chicago, IL 60611 and \\ ${ }^{2}$ Department of Neurobiology, Weinberg College of Arts and Sciences, Northwestern University, Evanston, IL 60208
}

\begin{abstract}
Fragile $\mathrm{X}$ syndrome (FXS) is the most common form of inherited mental retardation and the most common known cause of autism. Loss of fragile X mental retardation protein (FMRP) in mice ( $F m r 1 \mathrm{KO})$ leads to altered synaptic and circuit maturation in the hippocampus that is correlated with alterations in hippocampal-dependent behaviors. Previous studies have demonstrated that loss of FMRP increased the rate of proliferation of progenitor cells and altered their fate specification in adult Fmr1 KO mice. While these studies clearly demonstrate a role for FMRP in adult neurogenesis in the hippocampus, it is not known whether the functional synaptic maturation and integration of adult-born dentate granule cells (abDGCs) into hippocampal circuits is affected in Fmr1 KO mice. Here, we used retroviral labeling to birthdate abDGCs in Fmr1 KO mice which allowed us to perform targeted patch clamp recording to measure the development of synaptic inputs to these neurons at precise time points after differentiation. The frequency and amplitude of spontaneous GABAergic events increased over the first three weeks after differentiation; however, this normal development of GABAergic synapses was not altered in Fmr1 KO mice. Furthermore, the relatively depolarized GABA reversal potential $\left(E_{\mathrm{GABA}}\right)$ in immature abDGCs was unaffected by loss of FMRP as was the development of dendritic arbor of the adult generated neurons. These studies systematically characterized the functional development of abDGCs during the first four weeks after differentiation and demonstrate that the maturation of GABAergic synaptic inputs to these neurons is not grossly affected by the loss of FMRP.
\end{abstract}

Key words: adult born neurons; fragile X; GABA; neurogenesis; synapse

\section{Significance Statement}

Loss of fragile $X$ mental retardation protein (FMRP) causes Fragile $X$ syndrome (FXS), a devastating neurodevelopmental disorder that causes multiple alterations in the development of synapses and neurons. Previous studies have described a role for FMRP in neurogenesis and hippocampal-dependent conditioning tasks linked to neurogenesis. This study systematically assessed the functional development of GABAergic inputs to adult born dentate granule cells (abDGCs) during the first four weeks after differentiation of adult neural stem cells in Fmr1 KO mice.

\section{Introduction}

Fragile $X$ syndrome ( $F X S$ ) is the most common known genetic cause of autism and intellectual disability. FXS is caused by the expansion of the CGG repeat in the 5' UTR of the Fmr1 gene, which leads to hypermethylation, tran-

Received April 6, 2018; accepted October 17, 2018; First published November 19, 2018.

The authors declare no competing financial interests. scriptional silencing, and loss of expression of the protein product, fragile $\mathrm{X}$ mental retardation protein (FMRP; Willemsen et al., 2011). FMRP is an RNA-binding protein that regulates a large number of mRNAs, many of which encode synaptic proteins. Dysregulated expression of synaptic proteins is thought to perturb synapse maturation

Author contributions: C.L.R. and A.C. designed research; C.L.R. performed research; C.L.R. and A.C. analyzed data; C.L.R. and A.C. wrote the paper. 
and plasticity; however, the specific mechanisms underlying synaptic and cognitive deficits in FXS remain unclear. There are a growing number of studies demonstrating that FMRP plays important roles in stem cells, including adult neural stem cells in the neurogenic niche in the subgranular zone (SGZ) of the hippocampus (Li and Zhao, 2014). The importance of adult-born dentate granule cells (abDGCs) to hippocampal function, memory processes, and potentially to several neuropsychiatric disorders (Gonçalves et al., 2016) has raised the possibility that alterations in neural stem cell proliferation and maturation and integration of abDGCs contribute to the pathology of FXS. Proliferation of adult neural progenitors is enhanced in mice lacking FMRP (Fmr1 KO; Luo et al., 2010; but also see Eadie et al., 2009), and fate specification is altered with fewer neural progenitors differentiating into neurons (Luo et al., 2010). In addition, it has been reported that reduced survival of adult-born neurons leads to an overall reduction in the number of DGCs in Fmr1 KO mice (Lazarov et al., 2012). Therefore, the evidence suggests that the number of abDGCs is reduced in Fmr1 KO mice and that FMRP ablation specifically in adult neural stem cells results in cell autonomous effects on proliferation, fate specification, and hippocampaldependent behaviors (Guo et al., 2011). Despite these known disruptions in neurogenesis in Fmr1 KO mice, an outstanding question is whether FMRP loss also affects how abDGCs mature and integrate into the hippocampal network after differentiation.

In many neuronal types, FMRP and related proteins play a role in neuronal development and synaptic function. There are alterations in the development of synapses particularly during early developmental critical periods in the cortex in Fmr1 KO mice (Nimchinsky et al., 2001; Cruz-Martín et al., 2010; Harlow et al., 2010). In several instances, these morphologic and functional changes normalize during development (Bureau et al., 2008); however, phenotypes associated with these circuits persist in adult Fmr1 KO mice (Arnett et al., 2014; He et al., 2017). abDGCs also undergo critical periods of development during the first few weeks after differentiation when they are undergoing synapse formation and dendritic remodeling (Bergami et al., 2015) and have elevated plasticity (Ge et al., 2007b). However, it remains unknown whether

This work was supported by the National Institutes of Health $(\mathrm{NIH}) / \mathrm{National}$ Institute of Mental Health (NIMH) Grant R21 MH104808 and the Department of Defense Grant W81XWH-13-ARP-IDA (to A.C.). C.L.R. was funded by the $\mathrm{NIH} / \mathrm{NIMH}$ Training Program in Neurobiology of Information Storage T32 $\mathrm{MH} 067564$ training grant and the $\mathrm{NIH} /$ National Center for Advancing Translational Sciences Training Program in Clinical and Translational Science TL1 8 UL1TR000150 training grant.

We thank Stephen Kraniotis for technical help and members of the Contractor and Swanson laboratories at Northwestern for helpful discussion.

Correspondence should be addressed to Anis Contractor, Department of Physiology, Northwestern University Feinberg School of Medicine, 303 East Chicago Avenue, Chicago, IL 60611, E-mail: a-contractor@northwestern.edu. https://doi.org/10.1523/ENEURO.0137-18.2018

Copyright (c) 2018 Remmers and Contractor

This is an open-access article distributed under the terms of the Creative Commons Attribution 4.0 International license, which permits unrestricted use, distribution and reproduction in any medium provided that the original work is properly attributed. loss of FMRP results in disruptions in synapse formation on abDGCs during this early developmental postmitotic period when they are actively integrating into the hippocampal network.

GABA synapses are the first inputs to form onto abDGCs and these synapses are initially excitatory due to a depolarized GABA reversal potential $\left(E_{\mathrm{GABA}}\right)$ that results from a relatively high intracellular chloride concentration in young neurons (Overstreet Wadiche et al., 2005; Ge et al., 2006). These earliest GABA inputs are important for survival, dendritic development, and subsequent formation and unsilencing of glutamatergic synapses (Ge et al., 2006; Chancey et al., 2013; Song et al., 2013; Alvarez et al., 2016). The distinct characteristics of immature abDGCs endow these cells with properties that create unique roles for them in information processing (Ge et al., 2007a). Ablation of adult neurogenesis leads to impaired trace and contextual fear conditioning and pattern separation, indicating that newly generated neurons play a distinct role in learning that cannot be replicated by mature or developmentally born DGCs (Shors et al., 2001; Clelland et al., 2009; Nakashiba et al., 2012). Interestingly, these same behaviors that have been shown to require intact adult hippocampal neurogenesis are impaired in the Fmr1 KO. Fmr1 KO mice have deficits in trace fear conditioning (Zhao et al., 2005), and this phenotype can be recapitulated by specific deletion of Fmr1 in adult neural stem cells (Guo et al., 2011). Therefore, while it is known that there are reductions in the number of abDGCs and correlated changes in behavior, it remains to be determined whether loss of FMRP results in changes in synaptic formation and maturation in abDGCs, which would alter their integration and activity in the hippocampal circuit.

Given the critical role of GABA signaling in early postmitotic maturation of abDGCs (Ge et al., 2006), and also the known alterations in GABA signaling during early postnatal development (He et al., 2014; Nomura et al., 2017) and in juvenile Fmr1 KO mice (Paluszkiewicz et al., 2011; Martin et al., 2014; Zhang et al., 2017), we investigated whether the time course of development of inhibition onto abDGCs is altered in Fmr1 KO mice.

\section{Materials and Methods}

\section{Animals}

All procedures related to the care and treatment of animals were performed in accordance with the Northwestern University Animal Care Committee's regulations. Fmr1 KO mice (C57BI/6) were maintained by breeding heterozygous females with WT or KO males. All experiments were performed blind to genotype in age-matched male littermates. Tail biopsies were used to perform post hoc genotyping of all mice used in the study.

\section{Retroviral birthdating}

A replication incompetent retrovirus based on Moloney murine leukemia virus (MMLV) expressing RFP was prepared as described (Tashiro et al., 2006, 2015). Briefly, HEK-293 cells stably expressing GP2 were cotransfected with RFP and VSVG using Lipofectamine 2000. The media 
were collected from transfected cells 3 and $6 \mathrm{~d}$ after transfection, filtered, and centrifuged at 25,000 rpm to precipitate the virus. Eight- to 10-week-old Fmr1 WT or $\mathrm{KO}$ males were anesthetized using ketamine/xylazine and $1 \mu \mathrm{l}$ of virus was injected bilaterally into the SGZ of the dentate gyrus at a rate of $\sim 0.3 \mu \mathrm{l} / \mathrm{min}$.

\section{Slice preparation and electrophysiology}

We prepared $250-\mu \mathrm{m}$ coronal slices at 14,21 , and 28 $( \pm 1)$ days postinjection (dpi). Slices were prepared using a Leica Vibratome in ice-cold high-sucrose artificial CSF (ACSF) containing the following: $85 \mathrm{mM} \mathrm{NaCl}, 2.5 \mathrm{mM}$ $\mathrm{KCl}, 1.25 \mathrm{mM} \mathrm{NaH}_{2} \mathrm{PO}_{4}, 25 \mathrm{mM} \mathrm{NaHCO}_{3}, 25 \mathrm{mM}$ glucose, $75 \mathrm{mM}$ sucrose, $0.5 \mathrm{mM} \mathrm{CaCl}_{2}$, and $4 \mathrm{mM} \mathrm{MgCl}_{2}$, equilibrated with $95 \% \mathrm{O}_{2}$ and $5 \% \mathrm{CO}_{2}$ and including 10 $\mu \mathrm{M}$ DL-APV and $100 \mu \mathrm{M}$ kynurenate. Slices were heated to $28^{\circ} \mathrm{C}$ in the same sucrose-ACSF, then the sucrose solution was gradually exchanged for recovery ACSF containing the following: $125 \mathrm{mM} \mathrm{NaCl}, 2.4 \mathrm{mM} \mathrm{KCl}, 1.2 \mathrm{mM}$ $\mathrm{NaH}_{2} \mathrm{PO}_{4}, 25 \mathrm{mM} \mathrm{NaHCO}_{3}, 25 \mathrm{mM}$ glucose, $1 \mathrm{mM} \mathrm{CaCl}$, $2 \mathrm{mM} \mathrm{MgCl}_{2}, 0.01 \mathrm{mM} \mathrm{dL}-\mathrm{APV}$, and $0.1 \mathrm{mM}$ kynurenic acid.

After a 60-min recovery, individual slices were transferred to a recording chamber and continuously perfused with oxygenated ACSF containing $2 \mathrm{mM} \mathrm{CaCl}_{2}$ and $1 \mathrm{mM}$ $\mathrm{MgCl}_{2}$ at an elevated temperature of $32^{\circ} \mathrm{C}$. The dentate gyrus was visually identified and targeted recordings were made from RFP-expressing dentate granule cells. Recording electrodes were manufactured from borosilicate glass pipettes and had tip resistances of 4-6 $\mathrm{M} \Omega$ when filled with internal recording solution. For whole-cell recordings, internal recording solution contained the following: $95 \mathrm{mM}$ CsF, $25 \mathrm{mM} \mathrm{CsCl}, 10 \mathrm{mM}$ Cs-HEPES, $10 \mathrm{mM}$ Cs-EGTA, 2 mM NaCl, 2 mM Mg-ATP, 10 mM QX-314, 5 $\mathrm{mM}$ TEA-Cl, and $5 \mathrm{mM}$ 4-AP, $\mathrm{pH}$ adjusted to 7.3 with $\mathrm{CsOH}$. Data were collected and analyzed using pClamp 10 software (Molecular Devices). Neurons were voltageclamped at $-70 \mathrm{mV}$ to record spontaneous IPSCs (sIPSCs) and miniature IPSCs (mIPSCs), which were isolated by inclusion of D-APV $(50 \mu \mathrm{M})$, CNQX $(10 \mu \mathrm{M})$, and TTX (1 $\mu \mathrm{M})$ for mIPSCs. MiniAnalysis (Synaptosoft) was used to analyze sIPSCs and mIPSCs. For perforated patch recordings, the pipette solution contained the following: 150 $\mathrm{mM} \mathrm{KCl}$ and $100 \mathrm{mM}$ HEPES, $\mathrm{pH}$ adjusted to 7.2 with Tris- $\mathrm{OH}$. The pipette tip was filled with gramicidin-free $\mathrm{KCl}$ solution and then backfilled with solution containing gramicidin (100 $\mu \mathrm{g} / \mathrm{ml})$. GABAergic currents were evoked using a picospritzer to deliver a 50-ms puff of $10 \mu \mathrm{M}$ GABA in the presence of $50 \mu \mathrm{M}$ D-APV and $10 \mu \mathrm{M}$ CNQX. Responses were recorded at holding potentials between -100 and $0 \mathrm{mV}$. The GABA reversal potential was calculated as the $x$-axis intercept of the best-fit line of the current-voltage plot.

\section{Two-photon laser scanning microscopy}

Labeled abDGCs were patched in the whole cell configuration as described above with Alexa Fluor 488 dye $(50 \mu \mathrm{M})$ added to the internal solution. Dye was allowed to perfuse through the cell for $\sim 20$ min before image acquisition. Fluorescent images were acquired with picosecond pulsed excitation at $790 \mathrm{nM}$. Images of the soma and dendrites were acquired with $0.19-\mu \mathrm{m}^{2}$ pixels with $10-\mu \mathrm{s}$ pixel dwell time with 1.0- $\mu \mathrm{m}$ focal steps. Neuron Studio was used to create 3-D reconstructions of the dendrites and morphology analysis was performed in NeuronStudio (Wearne et al., 2005) and ImageJ.

\section{Data analysis}

Data analysis was performed using Microsoft Excel and OriginPro 2017 software. mIPSC and sIPSCs were analyzed using MiniAnalysis (Synaptosoft). Decay kinetics of mIPSC events was measured as the time to decay from $90 \%$ to $37 \%$ of the peak amplitude on the falling phase of the response. Comparisons were made with a MannWhitney $U$ test, unless otherwise indicated. Differences were considered significant when $p<0.05$. Data are shown as mean \pm SEM.

\section{Results}

\section{Development of spontaneous GABA currents in abDGCs in Fmr1 KO mice}

To identify and birthdate newborn DGCs, we injected a modified retrovirus expressing RFP into the SGZ of 8- to 10-week-old Fmr1 KO mice and WT littermates (Tashiro et al., 2015). Retroviral injection clearly labeled neurons located in the SGZ of the dentate gyrus (Fig. 1A). Evoked IPSCs have been detected in abDGCs as early as $7 \mathrm{dpi}$ (Ge et al., 2006) and in our recordings the earliest time point at which we consistently observed spontaneous inhibitory events was $14 \mathrm{dpi}$. Based on this we performed targeted patch-clamp recordings from RFP-expressing cells at 14, 21, and $28 \mathrm{dpi}$. We first measured the frequency of sIPSCs and mIPSCs at these time points. sIPSC frequency increased over time as abDGCs matured in both genotypes (Fig. 1B). Despite the known delays in maturation of properties of neurons in other cortical regions in Fmr1 KO mice, we found that there was no difference in the SIPSC frequency at any postdifferentiation age of abDGC tested spanning this early period of development of these neurons (14 dpi WT: $0.028 \pm 0.004$ $\mathrm{Hz}$; 14 dpi KO: $0.032 \pm 0.004 \mathrm{~Hz}, n=6 / 3$ (cells, animals respectively), $p=0.49$ Mann-Whitney $U$ test; 21 dpi WT: $0.480 \pm 0.074 \mathrm{~Hz}, n=14 / 7,21$ dpi KO: $0.468 \pm 0.070 \mathrm{~Hz}$, $n=15 / 9, p=0.95$ Mann-Whitney $U$ test; 28 dpi WT: 1.16 $\pm 0.031 \mathrm{~Hz}, n=12,4 \mathrm{KO}: 0.90 \pm 0.086 \mathrm{~Hz}, 11 / 6, p=0.70$ Mann-Whitney $U$ test; Fig. $1 B, D-F)$. In addition, we measured action potential independent spontaneous inhibitory events (mIPSCs) in abDGCs, which can be a good indicator of the number of inhibitory connections, or the release probability of those synapses. Again, we did not find a difference in the frequency of these events in comparisons between recordings in Fmr1 WT and Fmr1 KO mice at any of the ages tested (Fig. 1C,G-I). A comparison of the average mIPSC frequencies in each recording over time demonstrated an equivalent increase across this developmental period for abDGCs in both genotypes (Fig. 1C). Together, the lack of a difference in frequency of sIPSCs or mIPSCs during maturation of abDGCs indicates that there is no difference in the number of inhibitory synaptic connections in these neurons in the Fmr1 KO mice during the first 4 weeks after differentiation. 
A
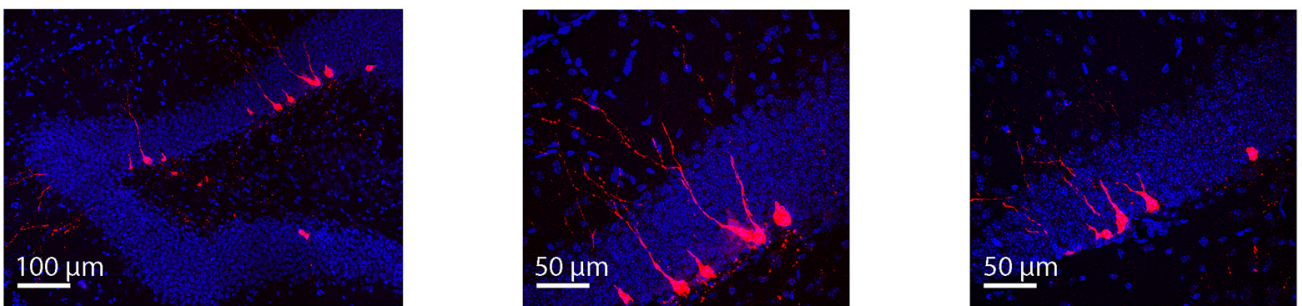

B

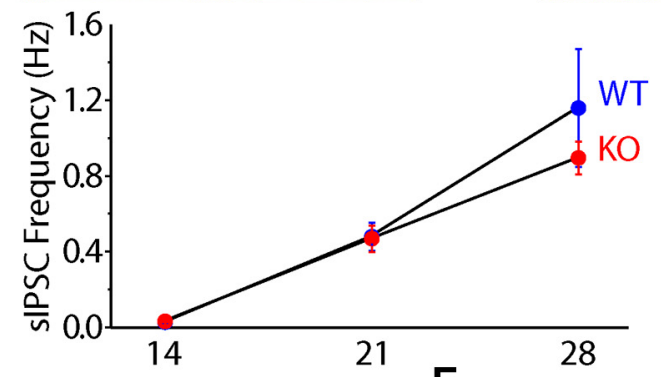

D 14 dpi sIPSCS
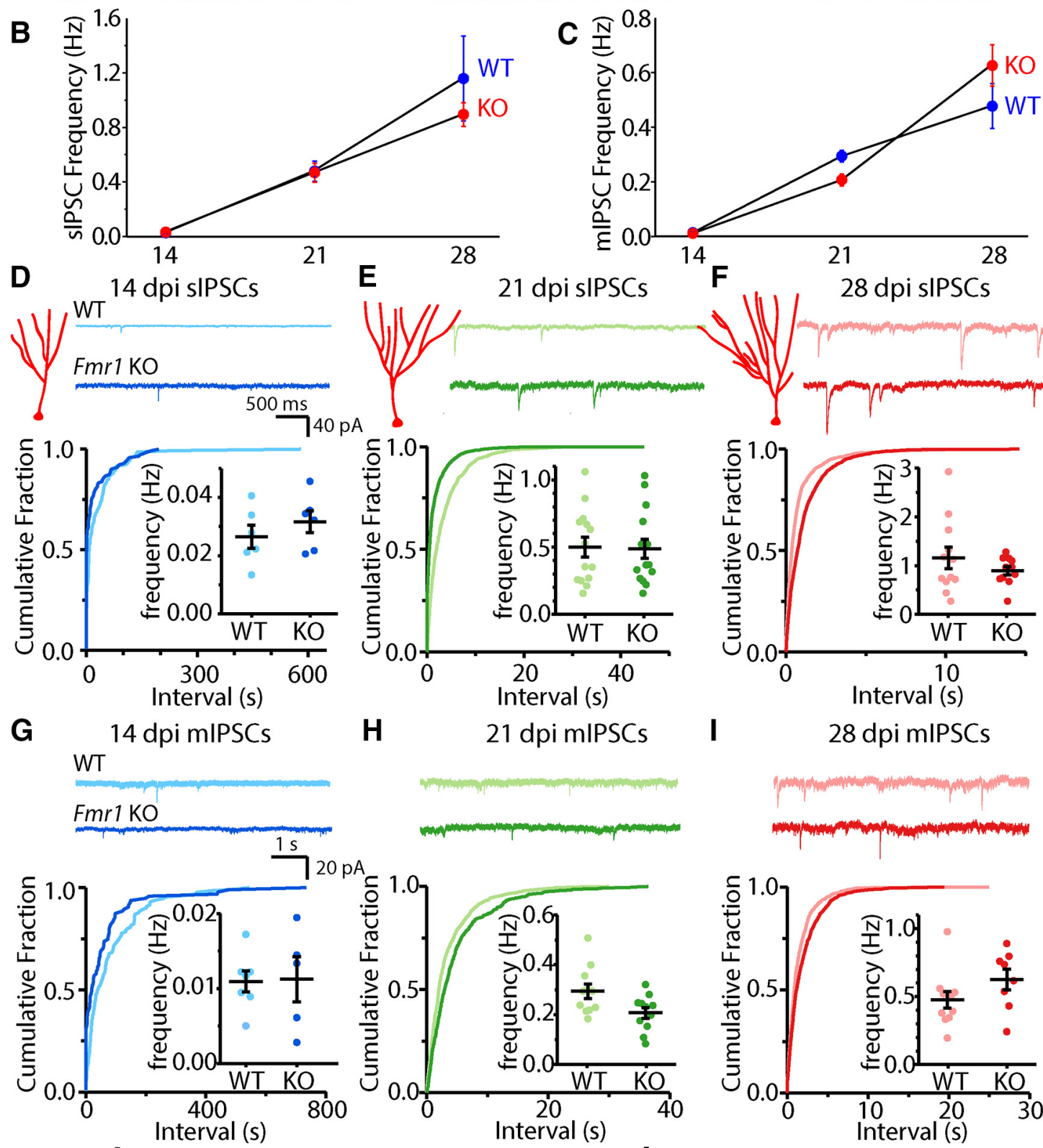

IUH 28 dpi sIPSCs

H

21 dpi mIPSCs
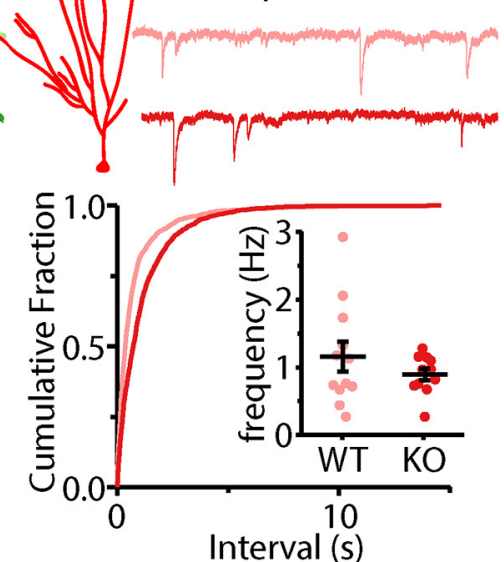

28 dpi mIPSCs

Figure 1. Frequency of sIPSCs and mIPSCs is not altered in abDGCs in Fmr1 KO. $\boldsymbol{A}$, Representative images of 21 dpi abDGCs virally labeled with RFP. Average sIPSC (B) and mIPSC (C) frequencies across all time points measured in Fmr1 WT (blue) and Fmr1 KO mice (red). $\boldsymbol{D}$, Schematic of dendritic morphology of abDGCs and representative traces (top panel), cumulative distribution of intereventinterval and average frequency of each recorded neuron (inset) of sIPSCs (bottom panel) at $14 \mathrm{dpi}, 21 \mathrm{dpi}(\boldsymbol{E})$ and $28 \mathrm{dpi}(\boldsymbol{F})$. $\boldsymbol{G}, \boldsymbol{H}$, $\boldsymbol{I}$, Representative traces, cumulative distribution of interevent-intervals and average frequency of mIPSCs in each recorded abDGC (inset) at 14,21 , and $28 \mathrm{dpi}$, respectively.

The amplitude of spontaneous events, particularly mIPSCs, is an indicator of the strength of individual synapses and is expected to increase as abDGCs undergo matura- tion (Ge et al., 2006). Comparison of the mIPSC amplitudes at each of the days postdifferentiation spanning this period again did not reveal any difference between re- 
A 14 dpi mIPSCs

Fmr1 WT Fmr1 KO
B $21 \mathrm{dpi} \mathrm{mIPSCs}$ Fmr1 WT Fmr1 KO
C 28 dpi mIPSCs

Fmr1 WT Fmr1 KO
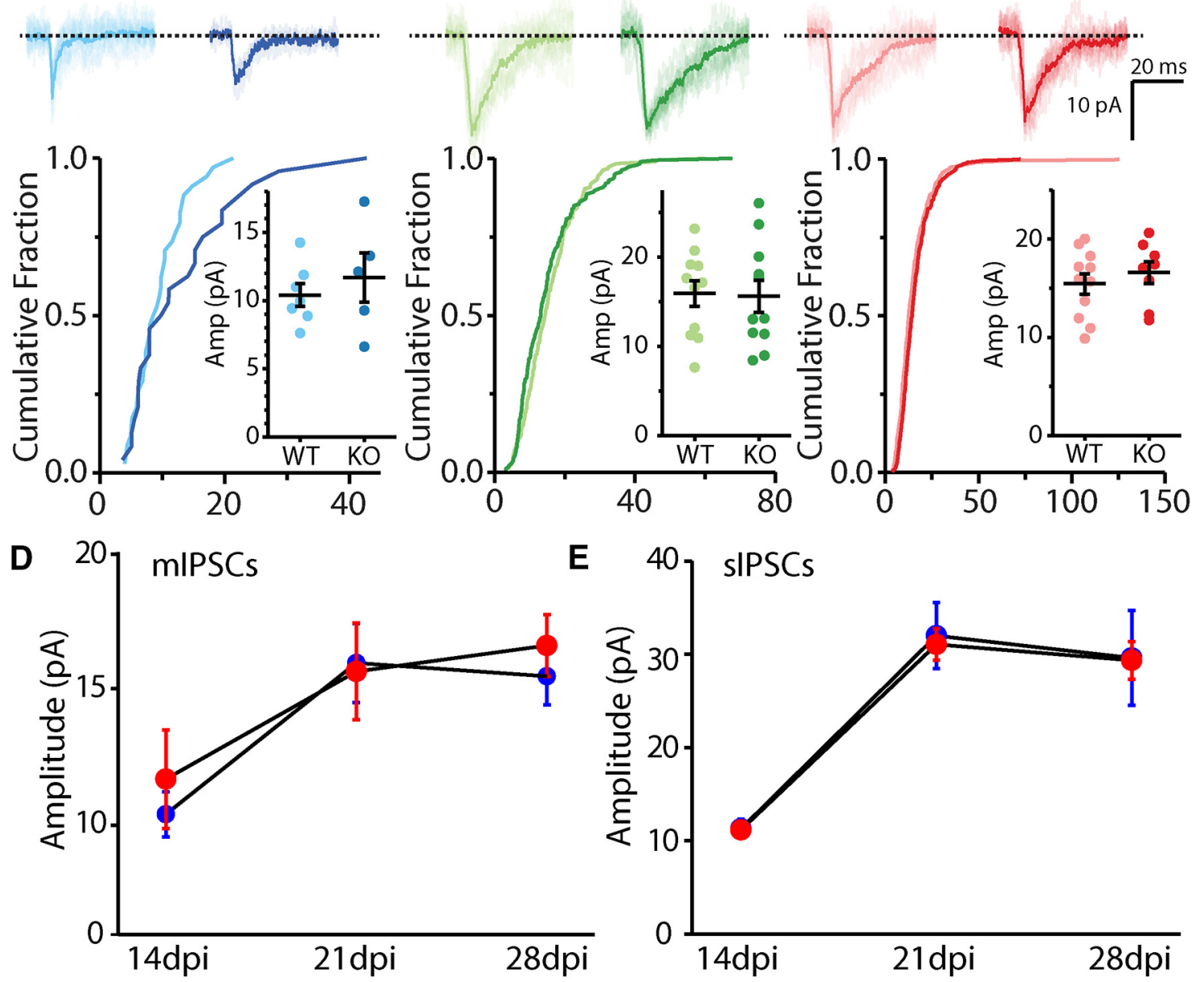

F 14 dpi mIPSCs $\quad$ G 21 dpi mIPSCs $\mathbf{H}$
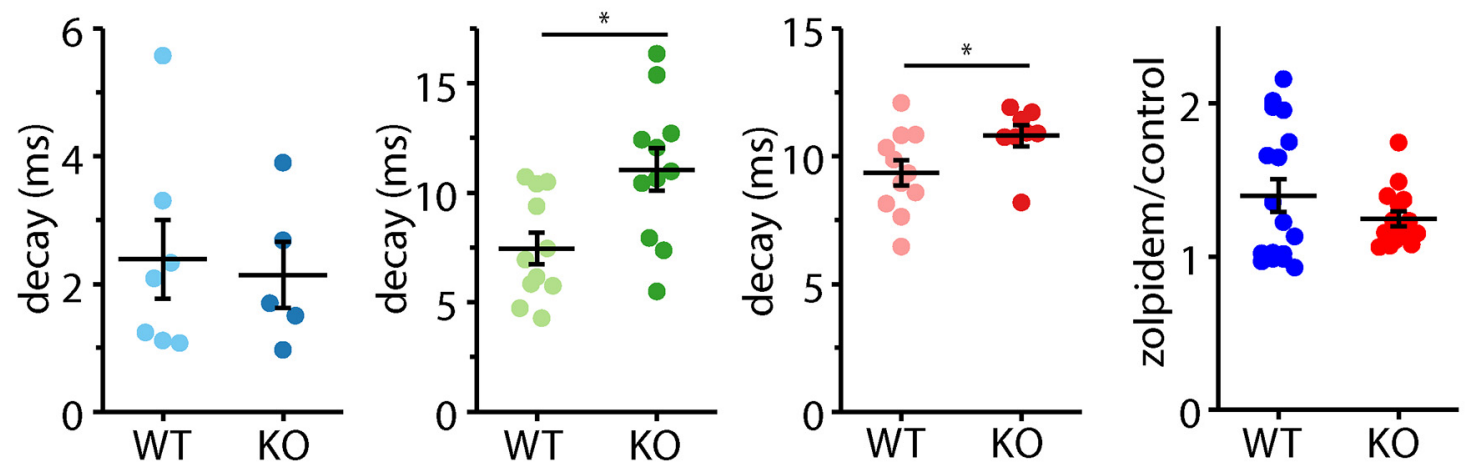

Figure 2. mIPSC amplitude is unaffected by loss of FMRP, but mIPSC decay is slower in abDGCs in Fmr1 KO. A, Representative traces of individual and averaged mIPSC events (top) and cumulative distribution and average amplitudes mIPSCs in each recording measured at $14 \mathrm{dpi}, 21 \mathrm{dpi}(\boldsymbol{B})$ and $28 \mathrm{dpi}(\boldsymbol{C})$ abDGCs. Average mIPSC amplitude $(\boldsymbol{D})$ and sIPSC amplitude $(\boldsymbol{E})$ across all time points measured in Fmr1 WT (blue) and KO (red). Average decay of mIPSCs in $14 \mathrm{dpi}(\boldsymbol{F}), 21 \mathrm{dpi}(\boldsymbol{G})$, and $28 \mathrm{dpi}(\boldsymbol{H})$ abDGCs. $\boldsymbol{I}$, Average mIPSC decay with zolpidem normalized to decay pre-zolpidem $(* p<0.05$, Mann-Whitney $U$ test).

cordings in each of the genotypes (WT 14 dpi: $10.4 \pm$ $0.827 \mathrm{pA}, n=7 / 3$; KO $14 \mathrm{dpi}: 11.7 \pm 1.81 \mathrm{pA}, \mathrm{n}=, 5 / 5, p$ $=0.64$, Mann-Whitney $U$ test; WT $21 \mathrm{dpi}: 15.9 \pm 1.45 \mathrm{pA}$, $n=12 / 5$, KO 21 dpi: $15.6 \pm 1.78$ pA, $n=12 / 5, p=1.00$, Mann-Whitney $U$ test; WT 28 dpi: $15.4 \pm 1.04$ pA, $n=$ 11/4, KO 28 dpi: $16.6 \pm 1.13$ pA, $n=8 / 3, p=0.49$,
Mann-Whitney $U$ test; Fig. 2A-C). In addition, and consistent with no genotype-mediated changes in synaptic strength during the development of abDGCs in Fmr1 KO mice, there were no differences in the amplitude of SIPSCs (Fig. 2E). In recordings of both mIPSCs and SIPSCs there was an equivalent increase of the average amplitude 
A

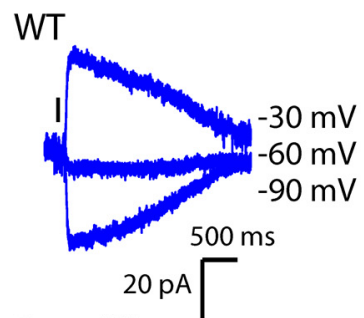

Fmr1 KO

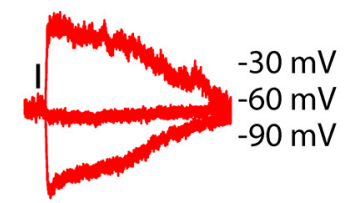

B

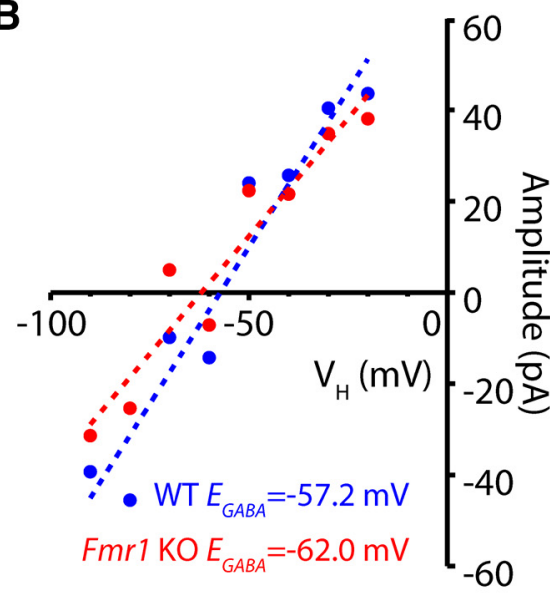

C

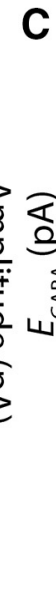

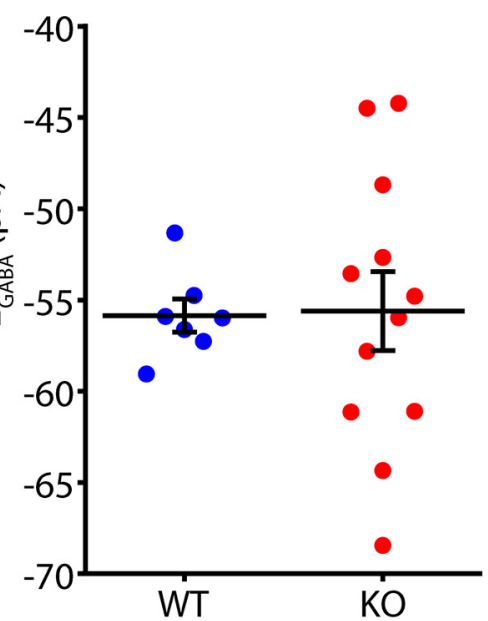

Figure 3. $E_{\mathrm{GABA}}$ in $21 \mathrm{dpi}$ abDGCs in Fmr1 KO and WT. $\boldsymbol{A}$, Representative traces of GABA responses from perforated-patch recordings in 21 dpi abDGCs in Fmr1 WT (top, blue) and Fmr1 KO (bottom, red) measured at three holding potentials (-30, -60 , -90 $\mathrm{mV})$. The response to a 50-ms puff of $10 \mu \mathrm{M}$ GABA was measured at several holding potentials in the presence of $50 \mu \mathrm{M}$ D-APV and $10 \mu \mathrm{M}$ CNQX. B, Representative current-voltage curves constructed from responses in two cells (blue WT, red KO). $E_{\mathrm{GABA}}$ was calculated as the $x$-axis intercept of the best-fit line of the current-voltage plot. $\boldsymbol{C}$, Grouped $E_{\mathrm{GABA}}$ data from all recordings.

of events in older neurons in both genotypes (Fig. 2D,E). Interestingly, at $14 \mathrm{dpi}$, the average amplitude for both mIPSCs and SIPSCs was similar, suggesting that at this time point presynaptic inhibitory neurons make a single synaptic connection per axon. However, the amplitudes diverged at $21 \mathrm{dpi}$, with sIPSC amplitudes larger than those of mIPSCs, indicating that single presynaptic axons make multiple contacts onto abDGCs in these older neurons (Fig. 2D,E).

Measuring the decay of mIPSCs, we found that there was a significant increase in the decay time course as abDGCs matured in both genotypes that could be indicative of a change in the subunit composition of $G_{A B A} R s$ (Overstreet Wadiche et al., 2005). At the youngest time measured mIPSC decay was not significantly different in Fmr1 KO (WT 14 dpi: $2.39 \pm 0.612 \mathrm{~ms}, n=7 / 3$; KO 14 dpi: $2.15 \pm 0.517 \mathrm{~ms}, n=5 / 4, p=1.00$, Mann-Whitney $U$ test; Fig. 2F). However, at older ages of abDGCs, the decay of mIPSCs in Fmr1 KO neurons was slower (WT 21 dpi: $7.45 \pm 0.722 \mathrm{~ms}, n=12 / 5$; KO: $11.1 \pm 0.987 \mathrm{~ms}, n$ $=12 / 5, p=0.008$, Mann-Whitney $U$ test; WT 28 dpi: 9.36 $\pm 0.492 \mathrm{~ms}, n=11 / 4$; KO 28 dpi: $10.8 \pm 0.410 \mathrm{~ms}, n=$ $8 / 3$ cells, $p=0.041$, Mann-Whitney $U$ test; Fig. $2 G, H$ ). In addition, sIPSC decay was not significantly different in Fmr1 KO (WT 14 dpi: $1.66 \pm 0.275$ ms, $n=6 / 3$; KO 14 dpi: $1.57 \pm 0.127 \mathrm{~ms}, n=6 / 3 ; p=0.7$, Mann-Whitney $U$ test; WT 21 dpi: $12.6 \pm 1.19$ ms, $n=14 / 8$; KO 21 dpi: 16.0 $\pm 1.39 \mathrm{~ms}, n=15 / 9, p=0.08$, Mann-Whitney $U$ test; WT 28 dpi: $14.2 \pm 1.32 \mathrm{~ms}, n=12 / 4$; KO 28 dpi: $13.3 \pm 0.80$ ms, $n=11 / 6$ cells, $p=0.651$, Mann-Whitney $U$ test).

Previous studies have found that the decay kinetics of sIPSCs are slower in abDGCs than in mature granule cells because of the incorporation of $\alpha 1$ subunit into postsynaptic $\mathrm{GABA}_{\mathrm{A}}$ receptors as neurons mature (Overstreet Wadiche et al., 2005). We tested whether the increased decay of the mIPSCs in abDGCs in Fmr1 $\mathrm{KO}$ mice might reflect a lower $\alpha 1$ subunit incorporation by measuring the effect of zolpidem, an $\alpha 1$-specific positive allosteric modulator, on the decay kinetics of mIPSCs. mIPSCs were recorded at $21 \mathrm{dpi}$ and the decay measured before and after the addition of $0.5 \mu \mathrm{M}$ zolpidem (Fig. 2I). We found that zolpidem lengthened mIPSC decay in 21 dpi abDGCs in both Fmr1 KO and WT to the same degree suggesting that $\alpha 1$ subunit content does not underlie the differences in decay observed in the Fmr1 KO mice (decay zolpidem/decay control WT: $1.40 \pm 0.11, n=17 / 7$; KO: $1.25 \pm 0.05, n$ $=15 / 7, p=0.87$, Mann-Whitney $U$ test).

\section{Maturation of the GABA reversal potential $\left(E_{\mathrm{GABA}}\right)$ in abDGCs}

As abDGCs mature the chloride reversal potential becomes progressively hyperpolarized in a similar manner to what occurs in other developing neurons (Ge et al., 2006; Chancey et al., 2013). The chloride equilibrium potential in large part determines the reversal potential for $\mathrm{GABA}_{\mathrm{A}}$ receptors $\left(E_{\mathrm{GABA}}\right)$ and therefore affects the strength of inhibitory transmission. $E_{\mathrm{GABA}}$ reaches its mature value 4 weeks after differentiation in abDGCs (Ge et al., 2006). Prior analysis of $F m r 1 \mathrm{KO}$ mice has demonstrated that $E_{\mathrm{GABA}}$ maturation is delayed in the developing cortex and hippocampus of Fmr1 KO mice (He et al., 2014; Tyzio et al., 2014). Therefore, we measured $E_{\mathrm{GABA}}$ using perforated patch recording from abDGCs $21 \mathrm{~d}$ after differentiation. In WT abDGCs the reversal potential was still depolarized from the mature value at this age (WT $E_{\text {GABA }}$ : $-55.9 \pm 0.91 \mathrm{mV}, n=7 / 3)$. However, this value did not differ from that recorded in abDGCs in Fmr1 $\mathrm{KO}$ animals (KO $E_{\text {GABA }}:-55.6 \pm 2.17 \mathrm{mV}, n=12 / 6, p=0.967$, Mann-Whitney $U$ test; Fig. $3 A-C$ ). Therefore, while the reversal potential for GABA is still relatively immature and depolarized in $21 \mathrm{dpi}$ abDGCs, there is no effect of the loss of FMRP on $E_{\mathrm{GABA}}$, as has been reported in other developing neurons. 
A

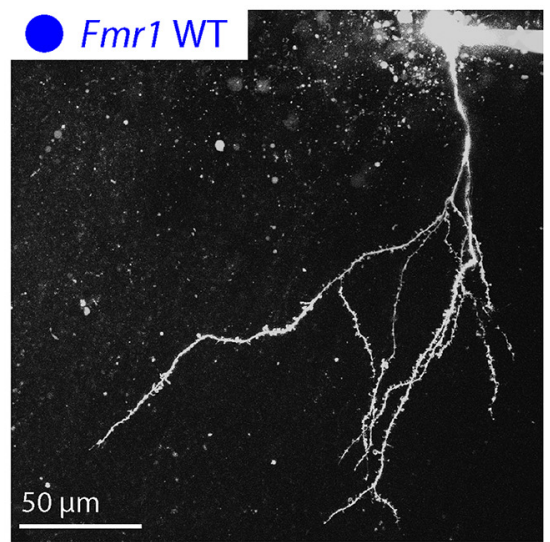

B

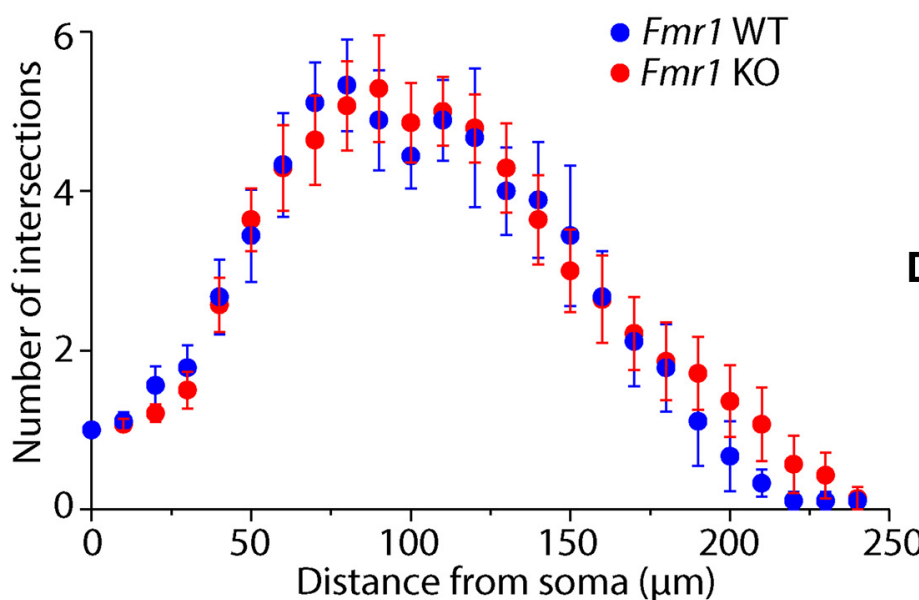

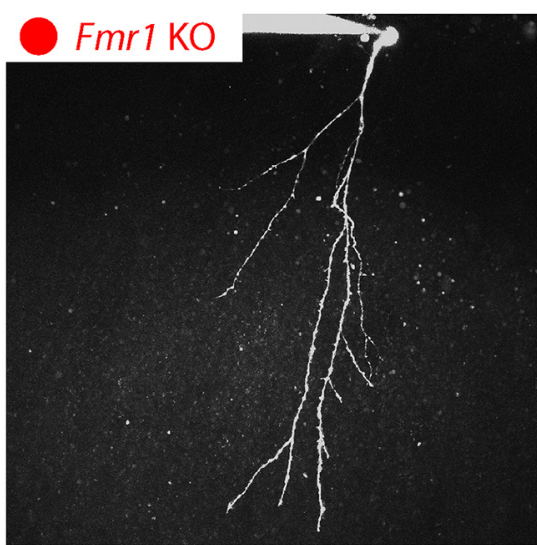

C
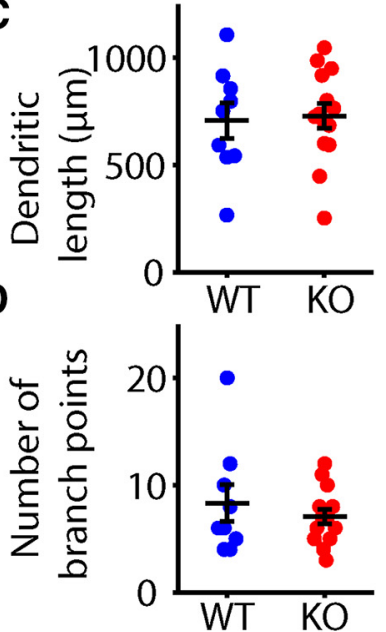

Figure 4. Morphology of $21 \mathrm{dpi}$ abDGCs in Fmr1 KO and WT. A, Representative two-photon images of $21 \mathrm{dpi}$ abDGCs filled with Alexa Fluor 488 in slices from Fmr1 WT (right) and Fmr1 KO (left) mice. B, Sholl analysis of dendritic complexity of $21 \mathrm{dpi}$ abDGCs in Fmr1 WT (blue) and Fmr1 KO mice (red). Average total dendritic length $(\boldsymbol{C})$ and total number of branch points $(\boldsymbol{D})$ of $21 \mathrm{dpi}$ abDGCs in Fmr1 WT (blue) and Fmr1 KO (red) mice.

\section{Development of dendrites of abDGCs in Fmr1 KO mice}

Dendritic morphology of abDGCs resembles that of mature DGCs as early as $21 \mathrm{dpi}$, when distal dendrites reach the outer molecular layer and significant arborization is observed (Zhao et al., 2006). Dendritic spines begin to form around $16 \mathrm{dpi}$, consistent with the fact that glutamatergic signaling is rarely observed before $14 \mathrm{dpi}$ (Ge et al., 2006; Zhao et al., 2006). We thus sought to determine if loss of FMRP would lead to alterations in dendritic morphology in $21 \mathrm{dpi}$ abDGCs during this critical period of their development. abDGCs were filled with a morphologic dye and imaged using a two-photon microscope (Fig. 4A). Quantification of their dendritic complexity at 21 $\mathrm{dpi}$, as assessed by Sholl analysis did not uncover any significant difference between the genotypes (two-way ANOVA for unbalanced design, $p=0.999$ for genotype $\times$ radius interaction; Fig. $4 B$ ). In addition, measurement of total dendritic length did not reveal any difference in 21 dpi abDGCs in Fmr1 KO (WT: $701 \pm 94.2 \mu \mathrm{m}, n=8 / 5$; KO: $729 \pm 57.5 \mu \mathrm{m}, n=15 / 8, p=0.781$, Mann-Whitney $U$ test), and there was no difference in the number of dendritic branch points in Fmr1 KO at 21 dpi (WT: $8.63 \pm$
1.92, $n=9 / 5$, KO: $7.20 \pm 0.66, n=14 / 8, p=0.917$, Mann-Whitney $U$ test; Fig. $4 C, D$ ).

\section{Discussion}

In this study, we set out to systematically describe the development of abDGCs in the Fragile $\mathrm{X}$ mouse model, focusing on the formation of GABAergic inputs to these neurons during the first few weeks after differentiation. There are multiple studies that have found that loss of FMRP can delay neuronal development in the Fragile $X$ brain, therefore, a similar delay in development of abDGCs could have an impact on how these neurons become connected to hippocampal circuits, and how they contribute to circuit function. Studying GABA synapse development is particularly relevant as these are the first synapses to form onto abDGCs and GABA also produces a trophic effect on abDGCs (Ge et al., 2006; Song et al., 2013; Alvarez et al., 2016). Surprisingly, our data indicate that the development of inhibitory signaling onto abDGCs during the first four weeks is mostly unaffected by the loss of FMRP in the Fmr1 KO mice. Given the range of impairments in GABA signaling that have been described in the hippocampus of $F m r 1 \mathrm{KO}$ mice including altered expression of GABA receptor subunits and GAD 65/67, and the 
alterations in $E_{\mathrm{GABA}}$ in $F m r 1 \mathrm{KO}$ mice (Braat and Kooy, 2015a), it is surprising that GABA signaling appears to be unaltered in developing abDGCs during the critical period of their maturation.

\section{Critical period development and chloride homeostasis in Fragile $X$}

At the cellular level Fragile $X$ is a complex disorder because loss of FMRP leads to the dysregulation of expression of many neuronal proteins (Tang et al., 2015). The mouse model has been particularly useful in describing these complex alterations in neuronal development (Contractor et al., 2015). An important aspect that has emerged from some of these studies is the alterations in synaptic development of neurons during early critical periods in the cortex (Cruz-Martín et al., 2010; Harlow et al., 2010; Nomura et al., 2017). While these numerous delays in both excitatory and inhibitory neuron maturation have been well documented, up until now, it has not been established whether the development of abDGCs shows similar alteration in maturation to the developmentally generated neurons.

Among the known effects in developing neurons is the delay in the maturation of the GABA reversal potential in both the somatosensory cortex (He et al., 2014) and the hippocampus (Tyzio et al., 2014). In abDGCs, $E_{\mathrm{GABA}}$ has been demonstrated to be depolarized during early maturation in the weeks following differentiation (Tozuka et al., 2005; Ge et al., 2006) in a manner similar to developing neurons in other regions of the brain in perinatal mice. This occurs because of the relatively elevated intracellular chloride concentrations in abDGCs established by the juvenile chloride transporter NKCC1 (Ge et al., 2006). Disrupting chloride homeostasis in abDGCs leads to a profound alteration in the formation of synapses and in the maturation of the dendritic arbor. As there is growing evidence of altered $E_{\mathrm{GABA}}$ in developing neurons, we also measured $E_{\mathrm{GABA}}$ in abDGCs $21 \mathrm{~d}$ after differentiation when this measure is still maturing and not at its adult value (Ge et al., 2006). We confirmed that in $21 \mathrm{dpi}$ abDGCS in both WT and Fmr1 KO mice, the measured $E_{\mathrm{GABA}}$ is still relatively depolarized, but the values of $E_{\mathrm{GABA}}$ were not significantly different between the genotypes. Therefore, this crucial measure that regulates the strength of GABA signaling, and has a major impact on neuronal development, is not affected in abDGCs in Fmr1 KO mice.

\section{GABA and Fragile $X$}

The sequence of the formation of inputs and neurotransmitter signaling onto abDGCs broadly reflects that of developing neurons in other brain regions, including the early establishment of tonic and phasic GABAergic signaling followed by the establishment of excitatory connections (Ge et al., 2007a). GABA has an established role in brain development affecting proliferation (LoTurco et al., 1995; Haydar et al., 2000), migration, and maturation of progenitors and neurons (Represa and Ben-Ari, 2005; Wang and Kriegstein, 2009). After postnatal development, there are multiple known defects in GABA signaling associated with Fragile $X$, including age- and region-specific changes in $\mathrm{GABA}_{\mathrm{A}}$ receptor subunit ex- pression (Braat and Kooy, 2015b), changes in tonic and phasic GABA currents onto excitatory neurons (Centonze et al., 2008; Curia et al., 2009; Olmos-Serrano et al., 2010; Zhang et al., 2017) as well as defects in interneurons themselves (Gibson et al., 2008; Nomura et al., 2017). Expression of several $\mathrm{GABA}_{\mathrm{A}}$ receptor subunits is reduced in the cortex, hippocampus, or forebrain of Fmr1 KO mice (El Idrissi et al., 2005; D'Hulst et al., 2006; Gantois et al., 2006; Adusei et al., 2010). Expression of the glutamate decarboxylase enzyme (GAD) responsible for converting glutamate to GABA is increased in the hippocampus, but decreased in the amygdala of $F m r 1 \mathrm{KO}$ mice (El Idrissi et al., 2005; Olmos-Serrano et al., 2010). Functionally, both the frequency and amplitude of mIPSCs and sIPSCs is reduced in the amygdala of juvenile Fmr1 KO mice (Olmos-Serrano et al., 2010); however, a similar alteration is not observed in the subiculum of older mice (Curia et al., 2009). In some cases, these alterations in GABAergic signaling occur only early in postnatal development (Adusei et al., 2010; Nomura et al., 2017). Thus, loss of FMRP clearly affects GABA signaling in the postnatal mouse brain, but whether this is also the case for abDGCs was not known. By mapping spontaneous events by recording both sIPSCs and mIPSCs at three time points after differentiation of abDGCs, we were able to establish how inhibitory synapses form onto these neurons. We found that in both genotypes the frequency of IPSCs increases over time as would be expected if new synapses were being formed over the post differentiation period we analyzed. Interestingly, the amplitude of both the sIPSC and mIPSC events increased between 14 and $21 \mathrm{dpi}$. The increase in the mean quantal size at this developmental time point suggests that individual synapses become stronger. At the earliest time points, the amplitude of both mIPSCs and sIPSCs is equivalent suggesting that presynaptic axons of the inhibitory cells make a single contact whereas by $21 \mathrm{dpi}$ the mean amplitude of sIPSCs is double the mean amplitude of quantal events, suggesting that the SIPSCs represent the release at multiple synapses. While again we did not observe any genotype differences in these parameters, we did observe consistent lengthening of the decay kinetics of mIPSCs in Fmr1 KO mice which were significant in recordings from both $21 \mathrm{dpi}$ and $28 \mathrm{dpi}$ neurons. Prior work that compared the decay kinetics of inhibitory events in abDGCs and mature granule neurons found that the sIPSCs in abDGCs are slower because of the subunit composition of postsynaptic $\mathrm{GABA}_{\mathrm{A}}$ receptors (Overstreet Wadiche et al., 2005). This study found that the zolpidem sensitivity of inhibitory events was increased in mature neurons suggesting that the $\alpha 1$ subunit is increasingly incorporated into neurons as they mature (Overstreet Wadiche et al., 2005). Given this, we considered the possibility that a reduction in the incorporation of the $\alpha 1$ subunit in abDGCs in Fmr1 KO mice could underlie the prolonged decay of mIPSCs in Fmr1 KO. However, we did not observe a significant difference in the effect of zolpidem on mIPSC decay in $21 \mathrm{dpi}$ abDGCs between Fmr $1 \mathrm{KO}$ and WT, indicating that a reduction in $\alpha 1$ expression is unlikely to underlie the changes in mIPSC decay. It is possible that 
alterations in expression of other GABA receptor subunits or even differences in the location of GABAergic synapses on developing neurons may underlie the observed change in mIPSC decays recorded by a somatic electrode. Interestingly, while prior work has reported that abDGCs lack expression of the GABA $\alpha 1$ subunit (Overstreet Wadiche et al., 2005), we found zolpidem had a significant effect on most mIPSCs in the $21 \mathrm{dpi}$ birth-dated neurons in both genotypes. This may reflect differences in the populations of neurons that were analyzed in the previous study which recorded from POMC-GFP labeled neurons which are a more heterogeneous aged group (Overstreet et al., 2004).

In addition to the measures of synaptic function, we also measured the dendritic arbor to quantify both the complexity as well as the total dendritic length in $21 \mathrm{dpi}$ abDGCs. A prior study has reported that selective deletion of FMRP in adult neural stem cells isolated from the dentate gyrus, as well as in situ, caused a reduction in both the dendritic complexity and total dendritic length when measured in neurons $56 \mathrm{~d}$ after differentiation (Guo et al., 2011). Dendritic length and complexity are also reduced in mice with knockout of the FMRP paralog FXR2P and double knockout of FXR2P and FMRP induced an additive effect on dendrites of abDGCs (Guo et al., 2015). In our experiments, we patched and filled abDGCs with morphologic dyes in live slices and imaged the dendritic arbor at $21 \mathrm{dpi}$. In these younger neurons, we did not observe any genotype related differences in the total dendritic length or complexity in $F m r 1 \mathrm{KO}$ mice. It is possible that this difference in our results and those of the earlier study is due to a dendritic phenotype that emerges later on in the development of FMRP lacking abDGCs. While there have also been reports of regionspecific or developmental age-specific alterations in dendritic spine density or immature spine morphology in Fmr1 $\mathrm{KO}$ mice, there is no consensus on the effect of loss of FMRP on dendritic spines (for review, see He and PorteraCailliau, 2013). While we did not examine this measure in these immature abDGCs, prior work has reported normal dendritic spines in the mature DG in Fmr1 KO (Grossman et al., 2010).

In summary, we performed a systematic analysis of the functional properties of GABAergic synapses in abDGCs during the first four weeks after differentiation in Fmr1 KO mice. While previous studies have demonstrated that cell proliferation and fate specification of adult neural stem cells is altered by FMRP loss, our data suggest that neurons that develop from these stem cells do not have major alterations in the maturation of their GABAergic synaptic inputs and dendrites during the first four weeks of their development.

\section{References}

Adusei DC, Pacey LK, Chen D, Hampson DR (2010) Early developmental alterations in GABAergic protein expression in fragile $X$ knockout mice. Neuropharmacology 59:167-171. CrossRef Medline

Alvarez DD, Giacomini D, Yang SM, Trinchero MF, Temprana SG, Büttner KA, Beltramone N, Schinder AF (2016) A disynaptic feedback network activated by experience promotes the integration of new granule cells. Science 354:459-465. CrossRef Medline
Arnett MT, Herman DH, McGee AW (2014) Deficits in tactile learning in a mouse model of fragile $X$ syndrome. PLoS One 9:e109116. CrossRef Medline

Bergami M, Masserdotti G, Temprana SG, Motori E, Eriksson TM, Göbel J, Yang SM, Conzelmann KK, Schinder AF, Götz M, Berninger B (2015) A critical period for experience-dependent remodeling of adult-born neuron connectivity. Neuron 85:710717. CrossRef Medline

Braat S, Kooy RF (2015a) The GABAA receptor as a therapeutic target for neurodevelopmental disorders. Neuron 86:1119-1130. CrossRef

Braat S, Kooy RF (2015b) Insights into GABAAergic system deficits in fragile $X$ syndrome lead to clinical trials. Neuropharmacology 88:48-54. CrossRef

Bureau I, Shepherd GM, Svoboda K (2008) Circuit and plasticity defects in the developing somatosensory cortex of FMR1 knockout mice. J Neurosci 28:5178-5188. CrossRef Medline

Centonze D, Rossi S, Mercaldo V, Napoli I, Ciotti MT, De Chiara V, Musella A, Prosperetti C, Calabresi P, Bernardi G, Bagni C (2008) Abnormal striatal GABA transmission in the mouse model for the fragile X syndrome. Biol Psychiatry 63:963-973. CrossRef Medline

Chancey JH, Adlaf EW, Sapp MC, Pugh PC, Wadiche Jl, OverstreetWadiche LS (2013) GABA depolarization is required for experience-dependent synapse unsilencing in adult-born neurons. J Neurosci 33:6614-6622. CrossRef Medline

Clelland CD, Choi M, Romberg C, Clemenson GD Jr, Fragniere A, Tyers $\mathrm{P}$, Jessberger S, Saksida LM, Barker RA, Gage FH, Bussey TJ (2009) A functional role for adult hippocampal neurogenesis in spatial pattern separation. Science 325:210-213. CrossRef

Contractor A, Klyachko VA, Portera-Cailliau C (2015) Altered neuronal and circuit excitability in fragile $X$ syndrome. Neuron 87:699715. CrossRef Medline

Cruz-Martín A, Crespo M, Portera-Cailliau C (2010) Delayed stabilization of dendritic spines in fragile X mice. J Neurosci 30:77937803. CrossRef Medline

Curia G, Papouin T, Séguéla P, Avoli M (2009) Downregulation of tonic GABAergic inhibition in a mouse model of fragile $X$ syndrome. Cereb Cortex 19:1515-1520. CrossRef

D'Hulst C, De Geest N, Reeve SP, Van Dam D, De Deyn PP, Hassan BA, Kooy RF (2006) Decreased expression of the GABAA receptor in fragile X syndrome. Brain Res 1121:238-245. CrossRef Medline

Eadie BD, Zhang WN, Boehme F, Gil-Mohapel J, Kainer L, Simpson JM, Christie BR (2009) Fmr1 knockout mice show reduced anxiety and alterations in neurogenesis that are specific to the ventral dentate gyrus. Neurobiol Dis 36:361-373. CrossRef Medline

El Idrissi A, Ding XH, Scalia J, Trenkner E, Brown WT, Dobkin C (2005) Decreased GABA(A) receptor expression in the seizureprone fragile X mouse. Neurosci Lett 377:141-146. CrossRef Medline

Gantois I, Vandesompele J, Speleman F, Reyniers E, D'Hooge R, Severijnen LA, Willemsen R, Tassone F, Kooy RF (2006) Expression profiling suggests underexpression of the $G A B A(A)$ receptor subunit delta in the fragile $X$ knockout mouse model. Neurobiol Dis 21:346-357. CrossRef

Ge S, Goh EL, Sailor KA, Kitabatake Y, Ming GL, Song H (2006) GABA regulates synaptic integration of newly generated neurons in the adult brain. Nature 439:589-593. CrossRef Medline

Ge S, Pradhan DA, Ming GL, Song H (2007a) GABA sets the tempo for activity-dependent adult neurogenesis. Trends Neurosci 30: 1-8. CrossRef

Ge S, Yang CH, Hsu KS, Ming GL, Song H (2007b) A critical period for enhanced synaptic plasticity in newly generated neurons of the adult brain. Neuron 54:559-566. CrossRef

Gibson JR, Bartley AF, Hays SA, Huber KM (2008) Imbalance of neocortical excitation and inhibition and altered UP states reflect network hyperexcitability in the mouse model of fragile $X$ syndrome. J Neurophysiol 100:2615-2626. CrossRef Medline

Gonçalves JT, Schafer ST, Gage FH (2016) Adult neurogenesis in the hippocampus: from stem cells to behavior. Cell 167:897-914. CrossRef Medline 
Grossman AW, Aldridge GM, Lee KJ, Zeman MK, Jun CS, Azam HS, Arii T, Imoto K, Greenough WT, Rhyu IJ (2010) Developmental characteristics of dendritic spines in the dentate gyrus of Fmr1 knockout mice. Brain Res 1355:221-227. CrossRef Medline

Guo W, Allan AM, Zong R, Zhang L, Johnson EB, Schaller EG, Murthy AC, Goggin SL, Eisch AJ, Oostra BA, Nelson DL, Jin P, Zhao X (2011) Ablation of Fmrp in adult neural stem cells disrupts hippocampus-dependent learning. Nat Med 17:559-565. CrossRef Medline

Guo W, Polich ED, Su J, Gao Y, Christopher DM, Allan AM, Wang M, Wang F, Wang G, Zhao X (2015) Fragile X proteins FMRP and FXR2P control synaptic GluA1 expression and neuronal maturation via distinct mechanisms. Cell Rep 11:1651-1666. CrossRef Medline

Harlow EG, Till SM, Russell TA, Wijetunge LS, Kind P, Contractor A (2010) Critical period plasticity is disrupted in the barrel cortex of FMR1 knockout mice. Neuron 65:385-398. CrossRef Medline

Haydar TF, Wang F, Schwartz ML, Rakic P (2000) Differential modulation of proliferation in the neocortical ventricular and subventricular zones. J Neurosci 20:5764-5774. Medline

He CX, Portera-Cailliau C (2013) The trouble with spines in fragile X syndrome: density, maturity and plasticity. Neuroscience 251: 120-128. CrossRef Medline

He CX, Cantu DA, Mantri SS, Zeiger WA, Goel A, Portera-Cailliau C (2017) Tactile defensiveness and impaired adaptation of neuronal activity in the Fmr1 knock-out mouse model of autism. J Neurosci 37:6475-6487. CrossRef Medline

He Q, Nomura T, Xu J, Contractor A (2014) The developmental switch in GABA polarity is delayed in fragile $X$ mice. $J$ Neurosci 34:446-450. CrossRef Medline

Lazarov O, Demars MP, Zhao Kda T, Ali HM, Grauzas V, Kney A, Larson J (2012) Impaired survival of neural progenitor cells in dentate gyrus of adult mice lacking fMRP. Hippocampus 22:12201224. CrossRef Medline

Li Y, Zhao X (2014) Concise review: fragile $X$ proteins in stem cell maintenance and differentiation. Stem Cells 32:1724-1733. CrossRef Medline

LoTurco JJ, Owens DF, Heath MJ, Davis MB, Kriegstein AR (1995) GABA and glutamate depolarize cortical progenitor cells and inhibit DNA synthesis. Neuron 15:1287-1298. Medline

Luo Y, Shan G, Guo W, Smrt RD, Johnson EB, Li X, Pfeiffer RL, Szulwach KE, Duan R, Barkho BZ, Li W, Liu C, Jin P, Zhao X (2010) Fragile $\mathrm{x}$ mental retardation protein regulates proliferation and differentiation of adult neural stem/progenitor cells. PLoS Genet 6:e1000898. CrossRef Medline

Martin BS, Corbin JG, Huntsman MM (2014) Deficient tonic GABAergic conductance and synaptic balance in the fragile $X$ syndrome amygdala. J Neurophysiol 112:890-902. CrossRef Medline

Nakashiba T, Cushman JD, Pelkey KA, Renaudineau S, Buhl DL, McHugh TJ, Rodriguez Barrera V, Chittajallu R, Iwamoto KS, McBain CJ, Fanselow MS, Tonegawa S (2012) Young dentate granule cells mediate pattern separation, whereas old granule cells facilitate pattern completion. Cell 149:188-201. CrossRef Medline

Nimchinsky EA, Oberlander AM, Svoboda K (2001) Abnormal development of dendritic spines in FMR1 knock-out mice. J Neurosci 21:5139-5146. Medline

Nomura T, Musial TF, Marshall JJ, Zhu Y, Remmers CL, Xu J, Nicholson DA, Contractor A (2017) Delayed maturation of fastspiking interneurons is rectified by activation of the TrkB receptor in the mouse model of fragile X syndrome. J Neurosci 37:1129811310. CrossRef Medline

Olmos-Serrano JL, Paluszkiewicz SM, Martin BS, Kaufmann WE, Corbin JG, Huntsman MM (2010) Defective GABAergic neurotransmission and pharmacological rescue of neuronal hyperex- citability in the amygdala in a mouse model of fragile $X$ syndrome. J Neurosci 30:9929-9938. CrossRef

Overstreet LS, Hentges ST, Bumaschny VF, de Souza FS, Smart JL, Santangelo AM, Low MJ, Westbrook GL, Rubinstein M (2004) A transgenic marker for newly born granule cells in dentate gyrus. J Neurosci 24:3251-3259. CrossRef Medline

Overstreet Wadiche L, Bromberg DA, Bensen AL, Westbrook GL (2005) GABAergic signaling to newborn neurons in dentate gyrus. J Neurophysiol 94:4528-4532. CrossRef Medline

Paluszkiewicz SM, Olmos-Serrano JL, Corbin JG, Huntsman MM (2011) Impaired inhibitory control of cortical synchronization in fragile X syndrome. J Neurophysiol 106:2264-2272. CrossRef Medline

Represa A, Ben-Ari Y (2005) Trophic actions of GABA on neuronal development. Trends Neurosci 28:278-283. CrossRef Medline

Shors TJ, Miesegaes G, Beylin A, Zhao M, Rydel T, Gould E (2001) Neurogenesis in the adult is involved in the formation of trace memories. Nature 410:372-376. CrossRef Medline

Song J, Sun J, Moss J, Wen Z, Sun GJ, Hsu D, Zhong C, Davoudi H, Christian KM, Toni N, Ming GL, Song H (2013) Parvalbumin interneurons mediate neuronal circuitry-neurogenesis coupling in the adult hippocampus. Nat Neurosci 16:1728-1730. CrossRef Medline

Tang B, Wang T, Wan H, Han L, Qin X, Zhang Y, Wang J, Yu C, Berton F, Francesconi W, Yates JR 3rd, Vanderklish PW, Liao L (2015) Fmr1 deficiency promotes age-dependent alterations in the cortical synaptic proteome. Proc Natl Acad Sci USA 112:E4697E4706. CrossRef

Tashiro A, Zhao C, Gage FH (2006) Retrovirus-mediated single-cell gene knockout technique in adult newborn neurons in vivo. Nat Protoc 1:3049-3055. CrossRef

Tashiro A, Zhao C, Suh H, Gage FH (2015) Preparation and use of retroviral vectors for labeling, imaging, and genetically manipulating cells. Cold Spring Harb Protoc 2015:883-888. CrossRef Medline

Tozuka Y, Fukuda S, Namba T, Seki T, Hisatsune T (2005) GABAergic excitation promotes neuronal differentiation in adult hippocampal progenitor cells. Neuron 47:803-815. CrossRef Medline

Tyzio R, Nardou R, Ferrari DC, Tsintsadze T, Shahrokhi A, Eftekhari S, Khalilov I, Tsintsadze V, Brouchoud C, Chazal G, Lemonnier E, Lozovaya N, Burnashev N, Ben-Ari Y (2014) Oxytocin-mediated GABA inhibition during delivery attenuates autism pathogenesis in rodent offspring. Science 343:675-679. CrossRef Medline

Wang DD, Kriegstein AR (2009) Defining the role of GABA in cortical development. J Physiol 587:1873-1879. CrossRef Medline

Wearne SL, Rodriguez A, Ehlenberger DB, Rocher AB, Henderson SC, Hof PR (2005) New techniques for imaging, digitization and analysis of three-dimensional neural morphology on multiple scales. Neuroscience 136:661-680. CrossRef Medline

Willemsen R, Levenga J, Oostra BA (2011) CGG repeat in the FMR1 gene: size matters. Clin Genet 80:214-225. CrossRef Medline

Zhang N, Peng Z, Tong X, Lindemeyer AK, Cetina Y, Huang CS, Olsen RW, Otis TS, Houser CR (2017) Decreased surface expression of the $\delta$ subunit of the $\mathrm{GABA}_{\mathrm{A}}$ receptor contributes to reduced tonic inhibition in dentate granule cells in a mouse model of fragile X syndrome. Exp Neurol 297:168-178. CrossRef

Zhao C, Teng EM, Summers RG Jr, Ming GL, Gage FH (2006) Distinct morphological stages of dentate granule neuron maturation in the adult mouse hippocampus. J Neurosci 26:3-11. CrossRef

Zhao MG, Toyoda H, Ko SW, Ding HK, Wu LJ, Zhuo M (2005) Deficits in trace fear memory and long-term potentiation in a mouse model for fragile X syndrome. J Neurosci 25:7385-7392. CrossRef Medline 